EESTI NSV TEADUSTE AKADEEMIA TOIMETISED, V KÖIDE

BIOLOOGILINE SEERIA. 1956, NR. 4

ИЗВЕСТИЯ АКАДЕМИИ НАУК ЭСТОНСКОЙ ССР. ТОМ V

СЕРИЯ ВИОЛОГИЧЕСКАЯ. 1956, № 4

\title{
UHTLASTE OMADUSTEGA POOKEALUSTE KASVATAMISEST
}

\section{J. PALK}

Viljapuude majanduslike ja bioloogiliste omaduste varieerumine sordi piiris sõltub ebaühtlastest pookealustest, mis on kasvatatud juhuslikult kogutud seemnetest. Et saada võimalikult ühtlaste omadustega häid viljapuid, on tähtis kindlaks määrata viljapuude kasvutingimustele ja sortidele sobivad generatiivsed alusetüübid.

Tähelepanekud näitavad, et eri aastail või eri aedadest kogutud sama viljapuusordi vōi -vormi seemnetest kasvanud seemikud varieeruvad ühel aastal või juhul rohkem, teisel vähem. Sellest järeldub, et seemikute omaduste ühtlus ei sõltu alati ainult alusetüübist, ning see tõstis üles vajaduse töötada läbi võimalikult ühtlaste omadustega generatiivsete pookealuste kasvatamise küsimuse. Et selle küsimuse lahendamisel on küllaltki suur tähtsus, näitavad Eesti NSV Teaduste Akadeemia Taimekasvatuse Instituudi puuviljanduse sektoris ounapuude kultuursortidega korraldatud katsed.

Ise- ja risttolmlemise mõju selgitamine õunapuuseemikute kui pookealuste kvaliteedile toimus ainult ühe pookealuste kasvatamiseks sobiva, $\mathrm{ka}$ isetolmlemisel viljastuva õunapuusordi - «Antoonovka» seemikute juures. «Antoonovka» isetolmlemisest ja kolmest risttolmlemise kombinatsioonist («Aniis», «Sügisjoonik», «Leedu pepin») saadud seemnetest tärganud seemikud kasvatati ühtlastes agrotehnilistes tingimustes. Kõigist risttolmlemise kombinatsioonidest saadud «Antoonovka» seemned tärkasid varem ja seemikud kasvasid jõulisemalt kui isetolmlemisel saadud seemned ja seemikud. Sügisel oli «Antoonovka» isetolmlemisel saadud seemnetest kasvanud 86 üheaastase seemiku keskmine kõrgus $5,5 \mathrm{~cm}$, risttolmlemisel saadud seemnetest kasvanud 167 seemikul aga 14,0 cm.

Toodud andmed on veenvaks tõendiks, et risttolmlemine tõstab viljapuuseemikute elujōudu ja nende kui pookealuste kvaliteeti.

Et lahendada pookealuste kasvatamiseks hästi täiskasvanud,-raskemate seemnete saamise küsimus ning teada saada seemikute kasvutugevuse sõltuvust seemnete raskusest, koguti kolme õunapuusordi («Antoonovka», «Aniis», «Borovinka») vabal ja teatud isasortidega risttolmlemisel saadud erineva raskusega viljade seemned eraldi.

Selgus, et teatud isasordiga risttolmlemisel saadud raskemad viljad sisaldavad keskmiselt suurema arvu hästi täiskasvanud ja raskemaid seemneid kui väiksemad, kaalult kergemad viljad. Kolme sordi («Aniis», «Antoonovka», «Borovinka») vastastikusel risttolmlemisel saadud viljade seemnete kesknised mõõtetulemused on toodud tabelis 1 . 


\begin{tabular}{l|c|c|c}
\hline & \multicolumn{3}{|c}{ Vilja kaal } \\
\cline { 2 - 4 } & alla $50 \mathrm{~g}$ & $50-70 \mathrm{~g}$ & üle $70 \mathrm{~g}$ \\
\hline Hästi täiskasvanud seemne- & & & \\
te arv vilja kohta (tk.) & 4,0 & 5,2 & 6,75 \\
1000 seemne kaal (g) & 31,4 & 35,0 & 38,6
\end{tabular}

Täiendavalt läbiviidud katse näitas aga, et ühe sordi vabal risttolmlemisel (tavaliselt mitme isasordiga) saadud raskemates viljades ei ole hästi täiskasvanud seemneid alati rohkem kui kergemates viljades.

Et selgitada, kas seemikute kasvutugevus sõltub seemnete raskusest, kasvatati erineva raskusega viljadest kogutud seemnete seemikud risttolmlemise kombinatsioonide järgi ühtlastes agrotehnilistes tingimustes. Seemnete tärkamise ajas silmapaistvaid erinevusi ei olnud, kuid idulehtede perioodil hävis öökülmade tagajärjel 17\% kõige kergemate ja $3 \%$ kõige raskemate seemnete tõusmetest. Sügisel oli kõige raskematest ja kõige kergematest seemnetest kasvanud seemikute kõrguses silmaga märgatav erinevus. Vegetatsiooniperioodi lõpul mõõdeti seemikute kōrgus.

Kolme sordi («Aniis», «Antoonovka», «Borovinka») vastastikusel risttolmlemisel saadud erineva raskusega viljade seemnetest kasvanud seemikute keskmised mõõtetulemused on toodud tabelis 2 .

Tabel 2

\begin{tabular}{l|c|c|c}
\hline & \multicolumn{3}{|c}{ Vilja kaal } \\
\cline { 2 - 4 } & alla $50 \mathrm{~g}$ & $50-70 \mathrm{~g}$ & üle $70 \mathrm{~g}$ \\
\hline $\begin{array}{l}1000 \text { seemne kaal (g) } \\
\text { Oheaastaste seemikute kesk- } \\
\text { mine kōrgus (cm) }\end{array}$ & 10,7 & 35,0 & 38,6 \\
& 31,4 & 13,8 & 17,3
\end{tabular}

Tabelist nähtub, et risttolmlemise kombinatsioonil saadud suurematest viljadest kogutud raskemad seemned annavad pookealusteks elujōulisemaid (kvaliteetsemaid) seemikuid.

Märkimist väärivad veel õunapuuseemikute varieerumise põhjused. «Aniisi» ja «Antoonovka» seemikud olid haabituselt palju ühtlasemad, kui seemned koguti neil aastail, millal õied olid hästi arenenud, jõulised ja õitsemine kestis lühikest aega. See võis sõltuda emasordi elujõulisusest ja risttolmlemisest väheste isasortidega lühikesel õitsemisajal.

Lähtudes risttolmlemise positiivsest mõjust õunapuuseemikute kasvule, kerkis vajadus selgitada, kuivõrd ulatuslikult võiks ühe või teise õunapuusordi seemikutest I ja II valiku pookealuste väljatulek sõltuda tolmeldajast sordist. Vastavad katseandmed on toodud tabelis 3 .

Tabel 3

\begin{tabular}{|c|c|c|c|c|c|c|c|c|}
\hline Emasordid & \multicolumn{2}{|c|}{ «Aniis» } & \multicolumn{2}{|c|}{ «Borovinka» } & \multicolumn{2}{|c|}{ \&Antoonovka» } & \multicolumn{2}{|c|}{ «Leedu pepin» } \\
\hline Isasordid & 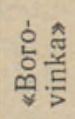 & 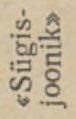 & 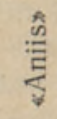 & 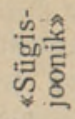 & 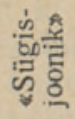 & 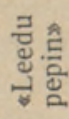 & 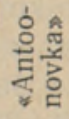 & 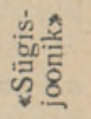 \\
\hline $\begin{array}{l}\text { Kaheaastaste I ja } \\
\text { II valiku pooke- } \\
\text { aluste väljatulek } \\
\text { tärganud seemiku- } \\
\text { te üldarvust }(\%)\end{array}$ & 87 & 84 & 81 & 64 & $62^{*}$ & $67^{*}$ & 89 & 63 \\
\hline
\end{tabular}

* «Antoonovka» seemikutest saadi pookealuseid vähe selle tõttu, et neid talvel kahjustasid hiired. 
Toodud andmetest nähtub, et mõnede pookealuste kasvatamiseks sobivate õunapuusortide («Aniis», «Antoonovka») seemikutest I ning II valiku pookealuste väljatulekule avaldasid isasordid vähest, teistele ( Borovinka», «Leedu pepin») aga tugevat mõju. Erinevate isasortide puhul «Borovinka» ja «Leedu pepini» seemikutest I ja II valiku pookealuste väljatulek kōikus vastavalt 17 ja 26 protsendi võrra. Parimateks tolmeldajateks nendele on vastavalt «Aniis» ja «Antoonovka». Isasortide vähene mõju «Antoonovka» ja «Aniisi» seemikutele sõltub arvatavasti nende sordiomaduste konservatiivsusest.

Eeltoodust järeldub, et erinevatel isasortidel on tugev, sagedasti negatiivne mõju mõne emasordi seemikute kui pookealuste omadustele. Seepärast tuleb senisest rohkem arvestada alusetüübi omadusi, leida sobiv tolmeldaja ning tagada sellega risttolmlemine.

Katsed näitasid, et teatud vanematepaari risttolmlemisel saadakse raskematest viljadest ka raskemad seemned ning et viimastest kasvab rohkem elujõulisi, pookealuste nõuetele vastavaid seemikuid. Seepärast tuleb seemne emapuude istandustes rakendada hea agrotehnika ja seemet koguda teatud vanematepaari risttolmlemisel saadud suurematest viljadest, mitte aga väiksematest ja praakviljadest, nagu tavaliselt tehakse viljapuuseemnete varumisel.

Eesti NSV Teaduste Akadeemia Taimekasvatuse Instituut

Saabus toimetusse 1. II 1956

\title{
О ВЫРАЩИВАНИИ ОДНОРОДНЫХ ПОДВОЕВ
}

\author{
Я. Ю. ПАЛЬК
}

Резюме

Варьирование хозяйственно-ценных и биологических свойств плодовых деревьев в пределах одного и того же сорта зависит от неоднородности подвоев, выращенных из случайно собранных семян. В целях предотвращения такого явления необходимо в первую очередь подобрать для возделываемых в данных условиях сортов соответствующие им формы генеративно размножаемого подвоя, дающего наиболее однородное хорошее потомство.

Проведенные в секторе плодоводства Института растениеводства АН Эстонской ССР опыты по выяснению пригодности в качестве подвоя сеянцев некоторых культурных сортов яблони показали, что перекрестное опыление в значительной степени повышает жизненность сеянцев. В то же время выяснилось, что различные опылители оказывают часто различное, а иногда (с точки зрения качеств подвоя) даже отрицательное влияние на формирование свойств сеянцев. Так, например, в результате оплодотворения некоторых сортов (Пепин литовский, Боровинка) пыльцой сорта Осеннее полосатое жизненность семенного потомства этих сортов оказалась пониженной, сеянцы отставали в росте, а выход подвоя первого и второго разбора оказался ниже нормального. Пепин литовский же (в качестве отцовского растения) передал сеянцам ряда сортов позднее прекращение вегетации и уход в зиму с частично неопавшими листьями. Отсюда следует, что нельзя ограничиваться одним только выделением лучших форм подвоя, а необходимо также подобрать соответствующие им сорта-опылители. Перекрестное опыление необходимо обеспечить 
путем закладки из выделенных материнских форм и сортов-опылителей специальных насаждений для производства семян.

Результаты опытов показывают также, что при перекрестном опылении определенных родительских пар тяжелые плоды содержат в среднем наибольшее количество полных семян, дающих наивысший процент сеянцев-подвоев I и II разбора. Исходя из этого, необходимо обеспечить в семенных насаждениях лучший агротехнический уход, а семена, при перекрестном опылении определенных форм, добывать только из крупных плодов, а не из мелких и бракованных, как это практикуется до последнего времени при заготовке семян.

Институт растениеводства Академии наук Эстонской ССР
Поступила в редакцию

1 II 1956

\section{UBER DAS AUFZIEHEN GLEICHARTIGER UNTERLAGEN}

\section{J. PALK}

\section{Zusammenfassung}

Die Ungleichartigkeit ökonomisch wertvoller und biologischer Eigenschaften der Obstbäume einer gegebenen Sorte hängt von Verschiedenheiten der Unterlagen ab, die aus wahllos gesammelten Samen aufgezogen werden. Um dieser Erscheinung vorzubeugen, ist es vor allem nötig, die der gegebenen Sorte am besten zusagende generative Unterlage $\mathrm{zu}$ ermitteln, die die beste und gleichartigste Nachkommenschaft sichert.

In der Sektion Obstbau des Instituts für Pflanzenbau der Akademie der Wissenschaften der Estnischen.SSR ist eine Leistungsprüfung der Sämlinge einiger Kultursorten des Apfelbaums in ihrer Eigenschaft als Unterlage durchgeführt worden. Es zeigte sich, dass Kreuzungsbestäubung die Lebensfähigkeit der Sämlinge beträchtlich steigert, dass aber verschiedene Bestäuber auf die Sämlinge eine verschiedene, des öfteren (vom Standpunkt der Eigenschaften als Unterlage) gar negative Wirkung ausüben. So hat sich z. B. bei der Bestäubung einiger Sorten («Litauischer Peping», «Borowinka») durch die «Gestreifte Herbstsorte» die Lebensfähigkeit der Nachkommenschaft als herabgesetzt erwiesen. Der «Litauische Peping» als Befruchter hingegen vererbte einer Reihe Sorten einen zu späten herbstlichen Vegetationsabschluss, wobei die Sämlinge zum Teil belaubt den Winter antraten. Hieraus folgt, dass es keineswegs genügt, bloss die besten Unterlagen zu wählen, dass aber auch die passendsten Partner für die Bestäubung ermittelt werden müssen. Die Kreuzungsbestäubung ist auf dem Wege zu sichern, dass die beiden Partnersorten in speziellen Pflanzungen zur Samengewinnung gezüchtet werden.

Die Versuche ergaben, dass es die schwersten Früchte sind, die bei der Kreuzungsbestäubung bestimmter Partner durchschnittlich die meisten vollwertigen Samen enthalten, die sich zu Unterlagen I und II Wahl herausbilden lassen. Demgemäss ist in den Pflanzungen für beste agrotechnische Pflege zu sorgen und sind die Samen nur aus den grössten Früchten auszulesen, nicht aber aus kleinen oder brackierten, wie es noch vielfach üblich ist.

Institut für Pflanzenbau

der Akademie der Wissenschaften der Estnischen SSR
Eingegangen am 1. Febr. 1956 